\title{
Evolution of the Macrostructure of Gray Cast Iron from Eutectic to Hypereutectic Composition
}

\author{
Marcos López ${ }^{\mathrm{a}^{*}}$, Juan M. Massone ${ }^{\mathrm{b}}$ and Roberto Enrique Boeri ${ }^{\mathrm{c}}$ \\ INTEMA, Universidad Nacional de Mar del Plata-CONICET, \\ Av. Juan B Justo 4302, Mar del Plata, B7608FDQ, Argentina. \\ amarcosl@fi.mdp.edu.ar, 'bmassonej@fi.mdp.edu.ar, cboeri@fi.mdp.edu.ar
}

Keywords: hypereutectic gray iron, coupled zone, austenite dendrites, kish graphite.

\begin{abstract}
This work studies the evolution of the macrostructure of gray cast iron as the carbon equivalent (CE) increases from near-eutectic to highly hypereutectic values. The macrostructure of spherical samples of flake graphite irons of CE ranging between $4.24 \%$ and $5.23 \%$ was revealed by using direct austempering after solidification technique (DAAS). The results were analysed by applying the concept of coupled zone for gray cast irons. The coupled zone is a region in the stable Fe-C-Si diagram in which solidification proceeds as a cooperative growth of both austenite and flake graphite. The coupled zone for gray cast iron is claimed to be asymmetrical as the eutectic reaction is extended towards the prolongation of the austenite liquidus line. All the samples investigated in the present study show the presence of relatively large austenite grains, demonstrating that the number of active nucleation sites of austenite per unit volume is small. The observation of the microstructure shows the presence of several units of coupled growth inside each austenite grain, what proves that many eutectic colonies have grown from the same austenite nucleus, even for highly hypereutectic compositions. Colour etching was employed to reveal the "hidden" dendrites present in the microstructure. The results suggest that proeutectic graphite is not a good nucleating agent for austenite. These results contribute to the understanding of the solidification of hypereutectic gray irons and verify the earlier understanding of the solidification of eutectic gray irons and its extension to hypereutectic compositions.
\end{abstract}

\section{Introduction}

The solidification of the eutectic formed by type A graphite and austenite, has been described in gray irons as a degenerate eutectic, in which austenite grows as dendrites $[1,2]$. In this case, the flake graphite is considered to be the leading phase. Hillert [3] discussed the current understanding on the solidification of eutectic gray cast iron and pointed out that early interrupted solidification experiments $[4,5]$ showed that the solidification of regular gray irons starts with the precipitation of austenite dendrites that later interact with graphite precipitates to form nearly spherical units called cells or colonies. Nevertheless, Hillert also points out that as the carbon equivalent (CE) increases, graphite should be the first phase to precipitate, and austenite dendrites should not form. However, the experimental studies about this matter find austenite dendrites for $\mathrm{CE}$ as high as 5.2\% [6]. This is in coincidence with more recent studies that showed the presence of large austenite grains in hypereutectic gray iron (GI) [7, 8]. In spite of this early knowledge, very often the solidification of eutectic and hypereutectic gray cast iron solidified with type A graphite is described to be dominated by the presence of eutectic colonies or cells, consisting of nearly spherical arrays of austenite and graphite, as shown schematically in Fig. 1 [1]. Stefanescu et al $[9,10]$ have developed a more complex explanation for the eutectic GI solidification, stating that eutectic cells nucleate and grow as independent units mostly in the liquid, but they also recognise the presence of a limited amount of primary austenite in eutectic GI that may solidify independently from the eutectic cells, depending on the cooling rate. Some other studies found in literature make no reference to the presence and influence of austenite dendrites at all, affirming that from each austenite nucleus a single eutectic cell is formed [11]. 


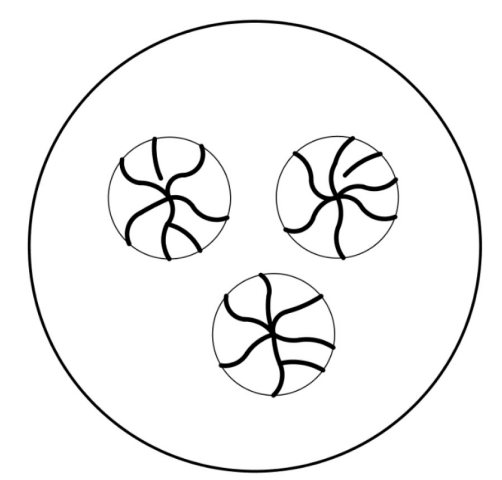

Fig. 1: Frequent representation of the solidification of eutectic and hypereutectic GI [1].

The analysis of the solidification of GI demands a clear understanding of the precipitation of solids around the austenite-graphite eutectic. Fredriksson $[1,2]$ showed that, as a consequence of the different growth kinetics of graphite and austenite, the coupled zone of Fe-C eutectic is asymmetrical, as shown in Fig. 2. Accordingly, the solidification of hypereutectic melts can proceed as represented in Fig. 3. As a liquid of $X_{0} C$ concentration is supercooled a certain $\Delta T_{G r}$, nucleation of graphite from the melt takes place (Point 1 in Fig. 3). As cooling proceeds, graphite grows in contact with the melt and the liquid will be progressively impoverished in $\mathrm{C}$. At some instance (Point 2 in Fig. 3) the melt will be supercooled enough with respect to the $\gamma$-Gr equilibrium temperature to nucleate and grow austenite. As austenite grows, the concentration of $\mathrm{C}$ in the melt grows, and the temperature may show recalescence as the austenite releases latent heat (Zone 3 of Fig. 3). Finally, as the melt concentration of $\mathrm{C}$ reaches the coupled growth zone, coupled growth will proceed until all liquid is exhausted. Consequently, the concept of an asymmetric coupled zone for GI explains the existence of primary (dendritic) $\gamma$ even for hypereutectic cast irons [12 - 14].

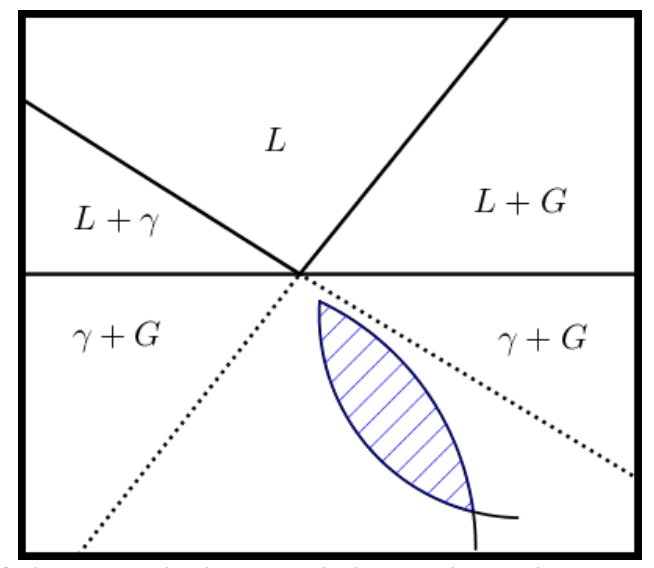

Fig. 2: Sketch of the shape of the coupled growth in GI based on Fredriksson [1, 2]. The extent of the coupled zone (shaded area) changes as a function of the growth rate. 


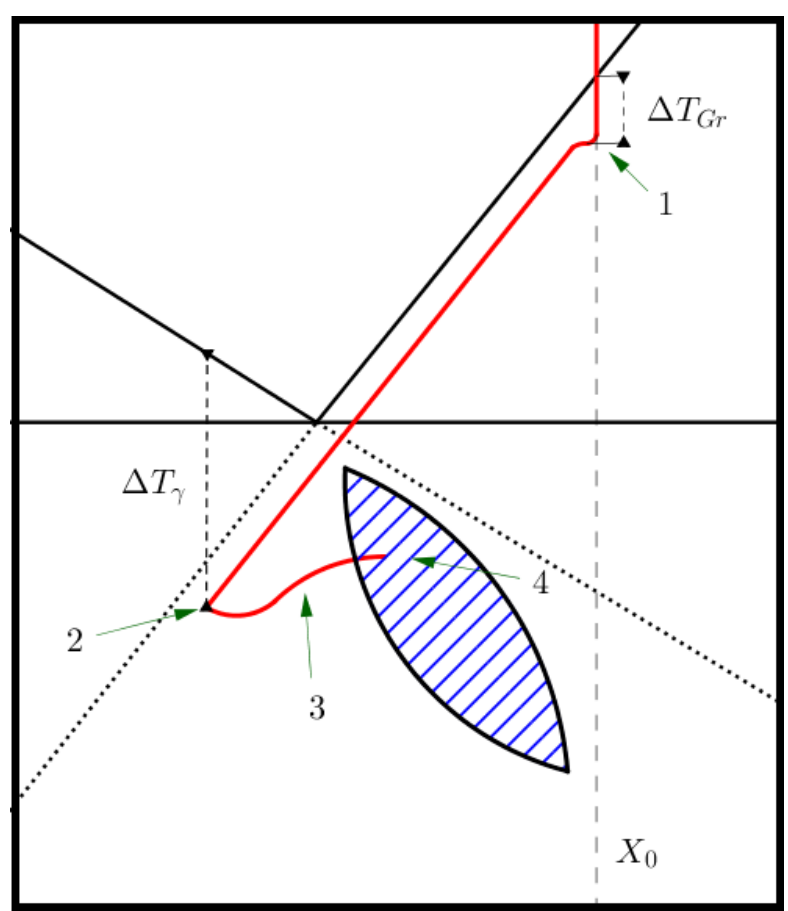

Fig. 3: Plot of the $\mathrm{C}$ concentration of the melt as solidification of hypereutectic GI proceeds.

Nevertheless, there are still some characteristics of the solidification that need to be examined. For instance, where and how does nucleation of austenite take place, and why are austenite dendrites not seen on hypereutectic irons. It is possible that they are too small or too thin to be observed, or they just involve too little volume. Perhaps the undercooling needed to nucleate austenite is too small, and coupled growth between austenite and graphite is established before the growth of austenite becomes noticeable. It is therefore clear that the solidification of hypereutectic cast iron needs further analysis.

The DAAS technique, a useful technique to reveal the solidification macrostructure of regularly solidified cast irons, is applied in the present study to analyse the macro and microstructures of near eutectic, hypereutectic and highly-hypereutectic cast irons cast in sand molds, in an attempt to gain further understanding on the solidification of flake graphite GI.

\section{Methodology}

Three melts were produced at the melting laboratory of INTEMA using a medium frequency $50 \mathrm{~kg}$ capacity induction furnace. Regular melting and metal treatment procedures were used. Melts were inoculated with $0,1 \% \mathrm{FeSi} 75$. In this study, $60 \mathrm{~mm}$ diameter spheres were cast in resin bonded sand molds. Faster cooling portions were produced by adding crests to the spheres. Fig. 4 shows the shape of the samples and the sectioning used to study the macro and microstructures. Table 1 indicates the chemical composition obtained for each heat produced. In all cases, small amounts of alloying elements were used, as these are necessary to provide sufficient hardenability to carry out the DAAS procedure. 

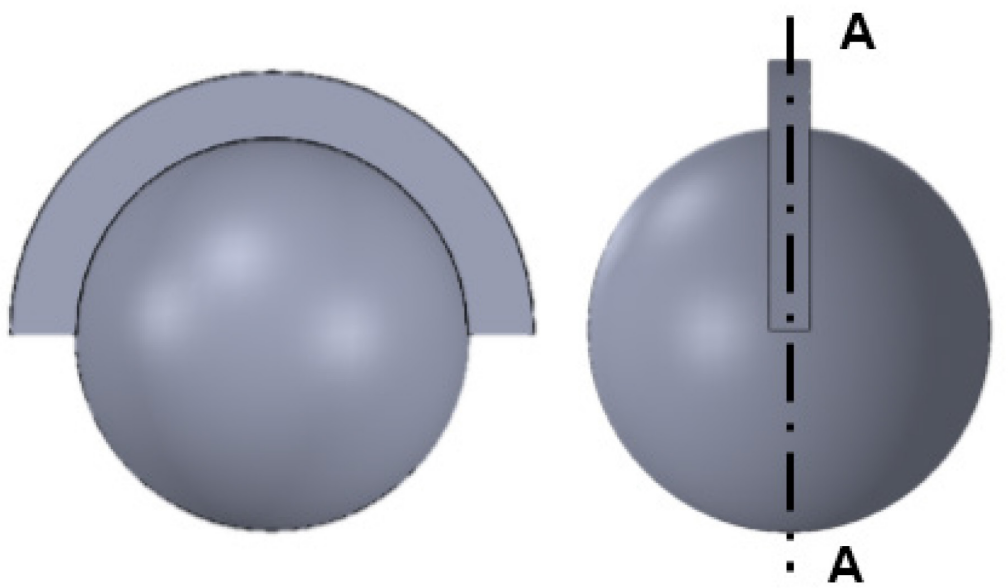

Fig. 4: Two different views of the $60 \mathrm{~mm}$ spherical samples used to cast the test samples. Line AA indicates the evaluated section.

Table 1: Chemical composition for the three melts produced.

\begin{tabular}{|c|c|c|c|c|c|c|c|c|c|}
\hline \multirow{2}{*}{ Heat } & \multicolumn{9}{|c|}{ Content (Wt\%) } \\
\cline { 2 - 10 } & $\mathbf{C E}$ & $\mathbf{C}$ & $\mathbf{S i}$ & $\mathbf{M n}$ & $\mathbf{C u}$ & $\mathbf{N i}$ & $\mathbf{M o}$ & $\mathbf{S}$ & $\mathbf{P}$ \\
\hline $\mathbf{A}$ & 4.24 & 3.25 & 2.96 & 0.48 & 0.67 & 0.48 & -- & 0.020 & 0.054 \\
\hline $\mathbf{B}$ & 4.67 & 3.75 & 2.75 & 0.45 & 0.65 & 0.79 & 0.21 & 0.014 & 0.035 \\
\hline $\mathbf{C}$ & 5.23 & 4.30 & 2.79 & 0.45 & 0.65 & 0.80 & 0.21 & 0.014 & 0.035 \\
\hline
\end{tabular}

After pouring the samples in alkyd resin bonded sand molds, they were let to solidify and then shaken out when their temperature was above $950{ }^{\circ} \mathrm{C}$, to be then transferred to a furnace at $920{ }^{\circ} \mathrm{C}$, and held there for 30 minutes to obtain a uniform temperature throughout the sample. Finally, the samples were transferred to a molten salt bath at $360{ }^{\circ} \mathrm{C}$ and held there for 60 minutes to complete the austempering involved in DAAS $[15,16]$.

The samples were then cut and polished using regular procedures. The observations were first carried out on unetched condition to characterise the graphite morphology. In this condition the amount of kish graphite particles per $\mathrm{mm}^{2}$ was measured for every melt by taking the average value from five different fields. Then regular nital $2 \%$ etching was employed to reveal the macrostructure, determining the austenite grain size according to ASTM E112. Finally, the samples were colour etched by employing Motz reagent to characterise the microstructure through the observation of the silicon segregation $[17,18]$. Si segregation traces the advance of solidification, so the colour etched microstructure obtained after the application of this reagent allows a better identification of the eutectic colonies and the austenite dendrites. The amount of eutectic colonies per $\mathrm{mm}^{2}$ was measured on the colour etched samples by considering the average value obtained from ten different fields.

\section{Results and Discussion}

The macrostructures of the investigated samples are shown in Fig. 5. All samples, regardless CE value, show relatively large grains. The grains correspond to volumes of primary austenite of a single crystaline orientation. The contrast between grains is not as good as that found in the macrography of other alloys because the amount of retained austenite present in the matrix, determined by visual inspection of the microstructure on the etched samples, is approximately just $30 \%$ of the total volume for all the melts. All samples show typical macrostructure features found in common metal alloys. Some zones, particularly near the surface and along the crest section, show much finer grain size as a consequence of the higher cooling rate. Columnar and equiaxed grain portions are also identified. The discussion of the reasons for the presence of equiaxed and columnar grains along these samples is beyond the scope of this study. 


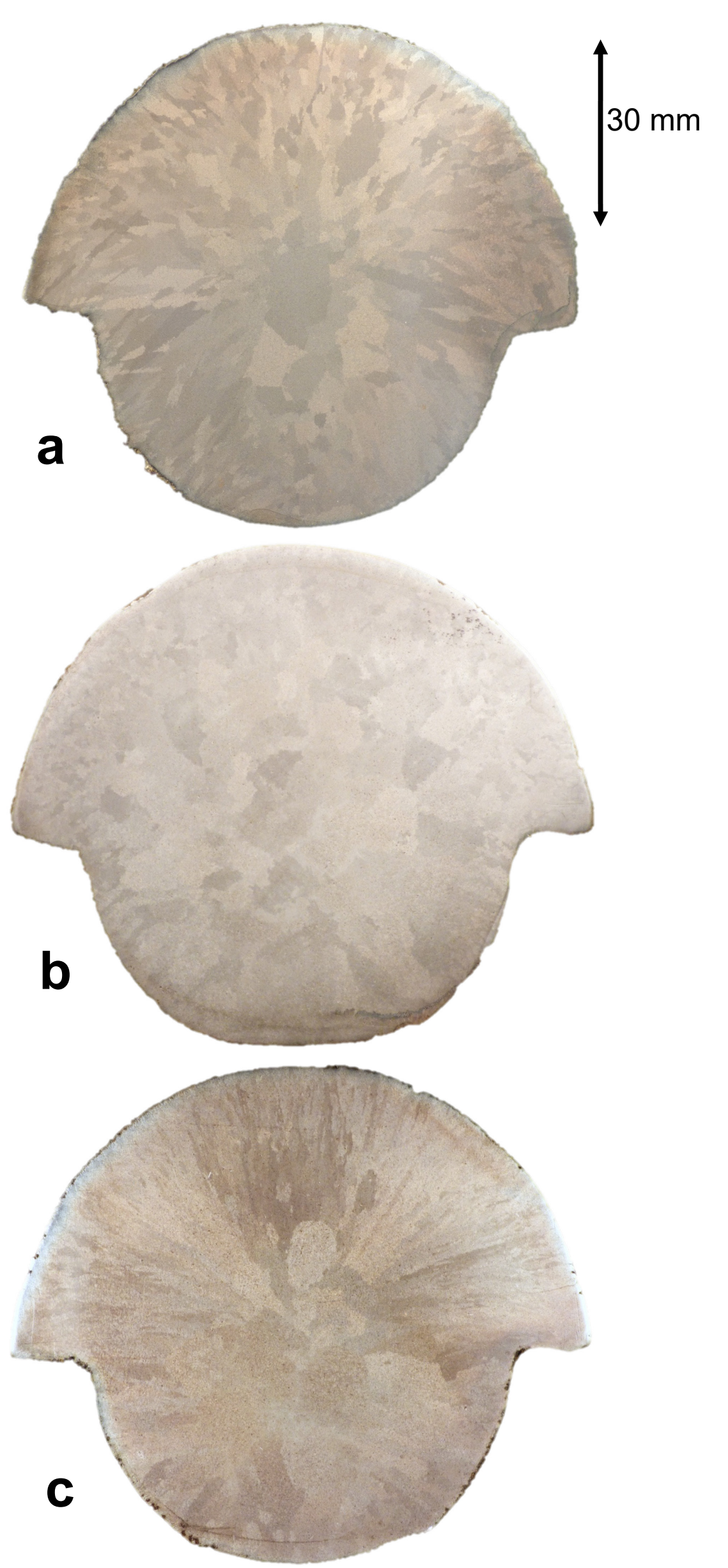

Fig. 5: Solidification macrostructures of samples from heat A (a), B (b) and C (c). 
The un-etched microstructure of the samples is shown in Fig. 6. As CE increases, the type of lamellar graphite changes from A to $\mathrm{C}$, as expected, and large proeutectic graphite precipitates (kish graphite) are present in considerable amounts, what seems to verify that the first solid phase that nucleates and grows in the melt is graphite. Some eutectic cells are also identified. No signs of primary austenite dendrites are evident. As the $\mathrm{CE}$ increases, graphite flakes tend to be straight, a characteristic already reported for hypereutectic GI [6].
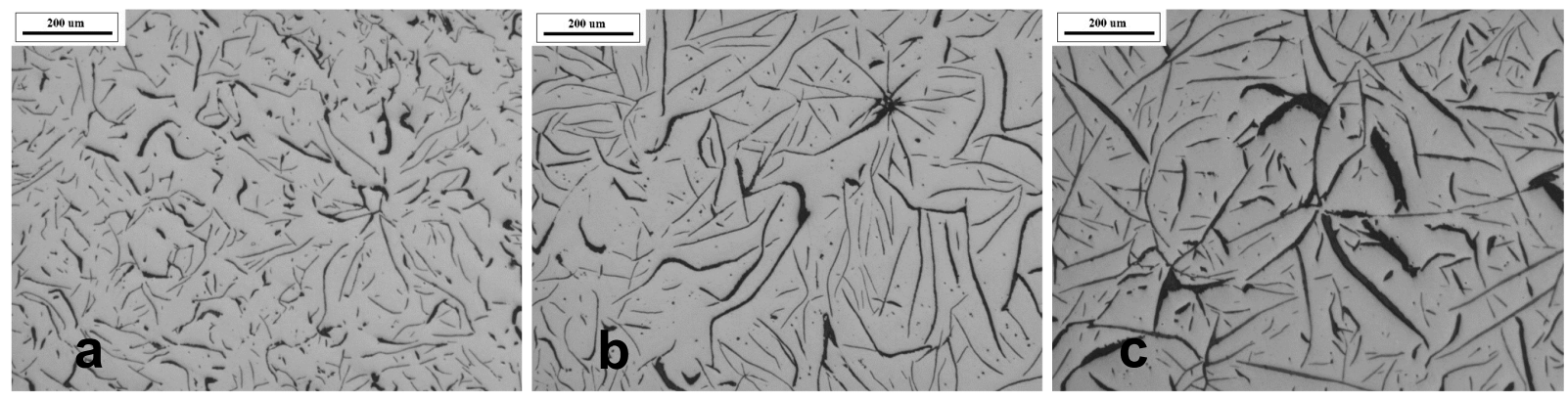

Fig. 6: Un-etched microstructures of samples A (a), B (b) and C (c).

Table 2 lists the average grain size, measured after applying DAAS, the average number of kish graphite per unit area, and the size of the larger eutectic cells. As already reported in earlier investigations, the size of the grains is much larger than the size of the eutectic cells $[15,16]$. On average, for the samples investigated there are 130 eutectic cells per section of a grain. In addition, there is a considerable number of primary (kish) graphite particles inside each austenite grain. This suggests that primary graphite has not been the nucleation site for austenite, or, at least, it is not a very successful site. According to Table 2, the presence of kish graphite in the hypereutectic samples $\mathrm{B}$ and $\mathrm{C}$ does not seem to influence in the amount and size of austenite grains and eutectic colonies.

Table 2: Average grain size, average number of kish graphite and eutectic cells per unit area for samples A, B and C.

\begin{tabular}{|c|c|c|c|}
\hline Melt & $\begin{array}{c}\text { Kish graphite } \\
\text { units per } \mathbf{~ m m}^{\mathbf{2}}\end{array}$ & $\begin{array}{c}\text { Eutectic cells per } \\
\mathbf{m m}^{\mathbf{2}}\end{array}$ & $\begin{array}{c}\text { Austenite grain size } \\
\text { (ASTM E112) }\end{array}$ \\
\hline A & 3 & 14 & M-7.0 \\
\hline B & 33 & 16 & M-6.0 \\
\hline C & 41 & 17 & M-6.5 \\
\hline
\end{tabular}

Fig. 7 shows some representative areas of the samples investigated after applying the Motz reagent. Fig. 7-a shows how effective is the colour etching as a tool to reveal the eutectic colonies. This figure, for hypereutectic sample B, shows nearly spherical colonies and no sign of dendrites. Nevertheless, as the sample is further examined, many regions showing clearly the interaction of austenite dendrites and eutectic colonies are found, as exemplified in Fig. 7-b for sample B. Similar microstructures can be found for highly hypereutectic sample $\mathrm{C}$ in Fig. 7-c and 7-d, where the interaction of eutectic colonies and austenite dendrites is clear. 

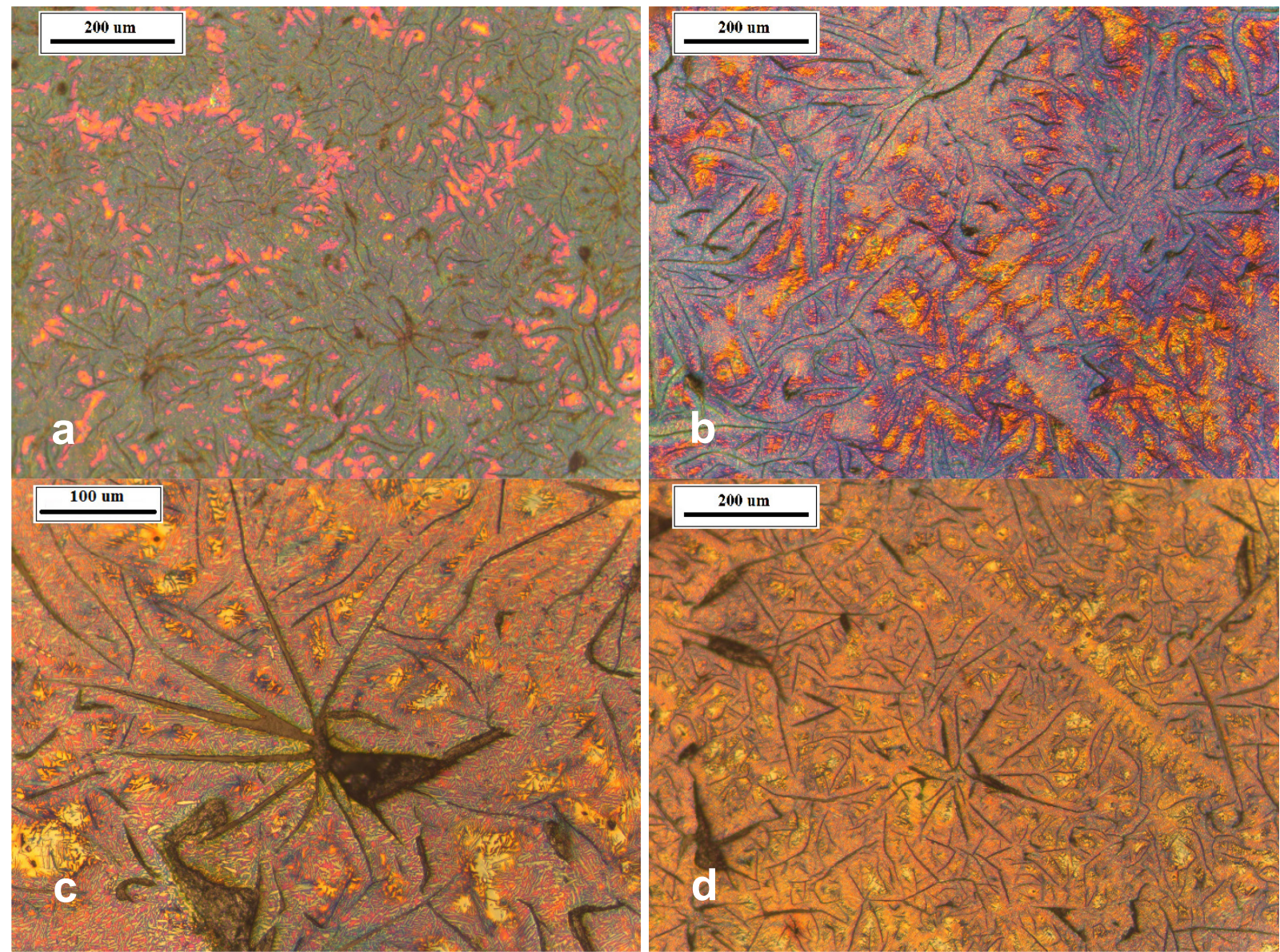

Fig. 7: Colour etched microstructures of samples B, (a) and (b), and C, (c) and (d).

The results of this investigation and the literature review suggest that the solidification of both eutectic and hypereutectic flake graphite cast iron takes place in agreement with the schematic shown in Fig. 3. Initial graphite nucleation for hypereutectic CE takes place in the liquid, as demonstrated by the kish morphology of the graphite. Later the austenite nucleates and grows freely in the melt to some extent, taking the shape of long dendrites (as suggested by the very large portions covered by the same grain). The nucleation of austenite appears to be independent from the prior precipitation of proeutectic graphite, as the density of kish graphite particles is much higher than the number of grains of austenite. Under the explanation proposed above, there is no expectation to find a CE content high enough to avoid the nucleation and dendritic growth of austenite from the melt.

\section{Summary}

- It has been verified that for gray irons of CE as high as 5.2 austenite grains are formed during the solidification. Very large grains of austenite are present in both eutectic and hypereutectic irons normally solidified in sand molds, validating earlier observations based on interrupted solidification and other techniques ${ }^{3-8}$.

- DAAS technique allowed to recognise the presence of dendritically grown portions of austenite in hypereutectic GI. Colour etching also revealed the presence of austenite dendrites for the hypereutectic samples obtained.

- It is apparent that proeutectic kish graphite, which is extensively found in the hypereutectic samples melt, does not act as a nucleation site for austenite. The amount of eutectic colonies neither seems to vary when kish graphite is present. 


\section{References}

[1] H. Fredriksson, U. Akerlind, Solidification and Crystallization Processing in Metals and Alloys, first ed., Wiley, United Kingdom, 2012.

[2] H. Fredriksson, The coupled zone in grey cast iron, Metall Trans A 6 (1975) 1658-1660.

[3] M. Hillert, Comments on "Eutectic solidification of gray cast iron", Acta Mater 52 (2005) $249-250$.

[4] A. Boyles, Trans AIME 125 (1937) 141.

[5] A. Hultgren, Y. Lindblom, E. Rudberg, J Iron Steel Inst 162 (1954) 365.

[6] H. Hanemann, A. Schrader, Atlas Metallographicus 2-3 (1936) Gebrüder Borntraeger, Berlin.

[7] G. Rivera, R. Boeri, J. Sikora, Solidification of gray cast iron, Acta Mater 50 (2004) 331-335.

[8] G. Rivera, P. Calvillo, R. Boeri, Y. Houbaert, J. Sikora, Examination of the solidification macrostructure of spheroidal and flake graphite cast irons using DAAS and EBSD, Mater Charact (2007) 1342-1348.

[9] D. Stefanescu, G. Alonso, P. Larrañaga, R. Suárez, On the stable eutectic solidification of iron-carbon-silicon alloys, Acta Mater 103 (2016) 103-114.

[10] D. Stefanescu, G. Alonso, P. Larrañaga, E. De la Fuente, R. Suárez, On the crystallization of graphite from liquid iron-carbon-silicon melts, Acta Mater 107 (2016) 102-126.

[11] E. Fras, M. Górny, Inoculation effects of cast iron, Archives of Foundry Engineering 12 (2012) 39-46.

[12] K. Pedersen, N. Tiedje, Solidification of hypereutectic thin wall ductile cast iron, Mater Sci Forum 508 (2006) 63-68.

[13] K. Olen, R. Heine, A revision of the Fe-C-Si system, Cast Metals Research Journal 4 (1968) 28-43.

[14] R. Heine, C. Loper, On dendrites and eutectic cells in gray iron, AFS Transactions 77 (1969) 185-191.

[15] G. Rivera, R. Boeri, J. Sikora, Revealing and characterising solidification structure of ductile cast iron, Mater Sci Tech Ser 18 (2002) 691-697.

[16] G. Rivera, R. Boeri, J. Sikora, Research advances in ductile iron solidification, AFS Transactions 111 (2003) 1-11.

[17] M. Motz, Microsegregation, an easily unnoticed influencing variable in the structural description of cast materials, Prakt Metallogr - Pr M 25 (1988) 285-293.

[18] G. Rivera, R. Boeri, J. Sikora, Revealing the solidification structure of nodular iron, Cast Metals 8 (1995) 1-5. 